\title{
Becoming More Culturally Aware in the University Classroom: Advice from a faculty member teaching in the Gulf Region
}

\author{
Dawn McBride \\ Zayed University, Abu Dhabi
}

Discuss this paper online at http://groups.yahoo.com/LTHE/

\begin{abstract}
This article will outline my experiences and offer practical recommendations when teaching in a university classroom when the professor and the students come from vastly different cultural backgrounds. I recently relocated from Canada to the United Arab Emirates (UAE) to teach female Muslim post secondary students - many of whom are the first in their family to receive higher education. Since it was difficult to find material on how to adapt one's teaching style to be more culturally sensitive in the university classroom, the intention of this article is to provide specific tips and strategies on how to adapt one's teaching style when immersed in an unfamiliar culture.
\end{abstract}

\section{Outline}

This article evolves around four themes. The first one addresses how to build trust and rapport with students who are from a culture unfamiliar to the professor. It is a process that requires a commitment to learn from the students. The next theme outlines three teaching strategies to assist one in presenting content in a more culturally sensitive manner. The third theme highlights how western philosophies and suppositions can be adapted to the Emirati/UAE culture. The final theme discusses ways to accommodate various Islamic practices in the university classroom. Each theme has a number of topics, with each one represented by a roman numeral. To begin, the theme of building a rapport with students to help create a classroom environment that fosters diversity and critical thought will be presented.

The following comments are based on my experience with students preparing for a career in a helping profession, such as social work or education. They cannot be generalized too far due to differences in dress, customs, and religious beliefs among Muslim women. However, the recommendations below can be used as a starting point to achieve success in a classroom where the professor has a different cultural background than the students, particularly when the students are Emirati. 


\section{Building Rapport with the Students}

Teaching is much more than a transferring of knowledge: as Ndura (2003) explains, it is about creating trust in the classroom. Students need to feel "respected, celebrated, and safe ... [and] feel their voice is heard and appreciated" (Marulis, 2000, p. 27) before they are willing to risk sharing their personal analysis of the material under study. To create trust, I draw from the work of a very influential counselling theorist: Carl Rogers. His therapeutic orientation stresses the need for the facilitator to be congruent, demonstrate empathic understanding and show unconditional positive regard (Rogers, 1980). The research by Herman and Bailey (1991) lends support for using Rogerian principles in the classroom, as they found successful overseas teachers possess many rapport-building characteristics such as being flexible, patient, understanding, and sensitive to their students' background.

As a professor, I aim to send a clear message that I take a "non-knowing" stance (Anderson \& Goolishiam, 1992) about my student's background and I welcome the process of getting acquainted with their dreams, hopes, feelings and thoughts. The long lasting benefit of taking this time to get to know them, particularly early in the term, is that they are often forthcoming in sharing their thoughts and feelings about their culture, religion and lifestyle. By learning more about their background, I am able to be more culturally sensitive to their needs and worldviews. As well, I can adapt my lectures to be more culturally relevant as I have gained a deeper understanding of their culture and lifestyle.

Five specific strategies used to gain the student's trust and respect are described in more detail in the following section. The connection between these strategies is that it requires the professor to have excellent listening skills and an ability to ask open ended questions in a non-judging manner. Interspersed in this section are additional teaching tips to increase the safety and efficiency of the mutual sharing process.

\section{Introductions}

I used the student's curiosity about myself and my background to create a game which allowed me to start the process of building rapport and to demonstrate that sharing opinions is a welcome activity in my classroom. The guessing game consists of having students guess various facts about my life and country of origin in a typical question-answer format (e.g., "how many children do I have?"). Other options include using fill-in the-blank handouts (e.g., Professor Dawn has children) and PowerPoint slides (e.g., a collage of pictures and students are invited to guess which pictures represent my family). This guessing game proved very successful, as the students became immediately engaged and animated - they were having fun guessing answers to my questions about my background. It was important 
to reinforce their participation, even if the answer was wrong, as I wanted to provide early evidence that their participation was always welcomed and not having the correct answer would not disappoint me. To do this, I acknowledged each guess by either a hand gesture such as thumbs up or giving verbal encouragement (e.g., "close - thanks for trying", "good guess", "you are really trying, aren’t you!" "what a great group for not giving up!").

There are two ground rules I have for sharing personal information in my classes. One, everyone has the right to pass (i.e., not answer a question). Two, no-one need share anything that they are even slightly doubtful about revealing. It is useful to remind students of these rules throughout the term.

\section{Get-to-know you questions}

In terms of understanding the student's world view as females practicing Islam in the UAE, I have found it useful to ask questions to help me understand who they are and what topics interest them. Some sample questions, always prefaced with the reminder that they have the right to pass and to provide as little or as much information as desired, are:

- Where were you born and raised? (I bring a map of the city, country and surrounding countries for students to visually identify where they were born and raised.)

- Tell me some things about your family that might be different for Canadian families. For example, how many people live in your home? Who prepares the meals?

- Share something about your daily routine so I can learn what your life is like. For example, what time do you like to get up in the morning? Go to bed? Do your homework? (I might share how their answers about their routine are the same or different from my students in Canada.)

- When you were 16 , what did you dream about? What magazines did you like to read?

- What do you like about living in the UAE?

By using these "get-to-know you questions", I discovered that they were extremely curious about parenting and problems that occur in marriage. Thus, where possible, I would link these topics into my lectures.

It has been my experience that it is much more efficient to use rounds than allow random answering as it is difficult to keep track of who has not answered and there may also be dead silence while you wait for a student to volunteer. A format that works well is to have one volunteer start the round and then work clockwise or counter clock wise. In attempt to reduce the power differential, I will often invite the student who volunteered to go first to 
chose the direction to proceed ("so, Fatima, since you started the round this morning, which direction should we proceed - to your right or to your left?"). I participate in the rounds and sometimes will elect to go first to role model an appropriate answer. For the first few weeks, I start each class with a "get-to-know you" question using the round format and then later space the questions to once a week or so.

\section{Get-to-know you worksheet}

I had students complete a worksheet during the first week that ask a series of questions about themselves, their career goals, etc (see Appendix A). The purpose of this worksheet is threefold: (a)to help me learn more about the students' background, what their interests and motivations are, etc, particularly if some students were not forthcoming in the early icebreaker rounds; (b) to gain insight into their level of writing and comprehension skills given English is their second language; and (c) to file the information for future reference so I can reacquaint myself when they visit me in my office during the semester and in the years to come.

\section{Constructing family trees (genograms)}

Constructing a family tree (known in psychology as a genogram) is a very common activity performed by professionals working within the health profession (for more detail on constructing genograms, please refer to McGoldrick et al., 1999). During the first week of classes, I ask students to construct a basic genogram of their family. This serves as an introduction to the technique and provides them with an applied skill within the first week of class, which they are often excited to learn and practice with others. Thus, I gain credibility in the classroom as they feel they have already learned something useful from me.

From a cultural awareness perspective, I gained considerable insight into the collectivist nature of the student's society. For example, I realized how large their families are, how many extended family members live in their home, and that students may have more than one mother as it is legal in this country, under Islamic law, for the husband to have up to four wives. This information translated into a deeper appreciation of how busy the students are attending family functions and how this collectivist nature can impact their studying at home. To be respectful of their time and of their culture, I inquired when they prefer to be given homework and discovered that most students like homework to be assigned during the week and given at least a week to complete it. 


\section{Using students' names}

Golden rules in teaching are remembering students' names and using them frequently in the classroom. My challenge was being able to pronounce the students' Arabic names. I use a variety of strategies to increase my exposure to hearing the unique pronunciation of their names:

- asking seasoned faculty/staff how to pronounce the names on my class list;

- inviting students to correct me each time I mispronounced their name

- asking students to state their name before answering the question during the rounds for the first month. Also, the repeated use of names helps to build group cohesiveness when the students do not know each other.

- and, to help me remember their names, I use name cards that sit on their desk (students write their names on heavy stock paper in large letters with a felt pen). A great organizational tip: Use different colors of paper per course to help identify which cards belong to which course. I also found it more convenient for the students if I keep the cards and distribute them at the start of the class;

\section{Addressing students: “Girls" vs. "students" or "ladies”}

I was surprised to learn that university staff and faculty routinely address students as "girls". During my university orientation, I was informed that female students expect to be addressed in this manner so it is permissible to continue this practice. To me, addressing post secondary students who are age 18 or older as "girls", some of whom are married and are mothers, not only adds to the power differential between professors and students, it reinforces the notion that women have less influence in society. Although women may have more obstacles than men in achieving equality, I wanted to support the work of the esteemed President of this country and his wife who are actively promoting women's freedom. Thus, I was uncomfortable addressing the students as "girls".

When I asked the students in my classes how they preferred to be addressed, many of them seemed surprised at being given a choice. They admitted it sounded strange to be addressed as ladies as in their culture, ladies is a term used to describe a married women. However, there was discussion that the term ladies awarded them some status as they felt they have more life experience than a girl.

A Native Arabic speaker I consulted, informed me that in her experience, young women do not refer to themselves as "girls" unless they are doing so in a joking manner. In a conversation with a male Arabic speaker who works at post secondary institution for males, he informed me that the male students are not referred to as "boys". Thus, based on the 
aforementioned reasons, I made a commitment to show the students respect by addressing them by their names, "ladies" or "students" when referring to them as a group. I sense pride in the students when I use the term "ladies" to address the class as they will make eye contact with me, smile, and generally seem pleased to be addressed in this form. This may seem a minor issue, but the time I took to learn how students preferred to be addressed and that I followed their request, allowed me to build a deeper rapport with them.

\section{Using Arabic in the classroom}

I admire the practices of one of my colleagues (Leon Fulcher) who often begins a lecture by greeting the students in Arabic. It acknowledges the student's Native language as well as demonstrates respect. Traditional greetings include "good morning" (Sabah alkhair), "good afternoon" (Masa alkhair) or Hello (marhaba or al salaam alaykum). Another common phrase that students will frequently use and seem to appreciate from the instructor is "God Willing" (Insha'allah) or "Thanks be to God" (al hamdulillah). These phrases can be contained within a slide presentation (overhead), verbally, or included in written feedback.

Once rapport has been established, it is often easier to adapt teaching strategies to teach in a more culturally sensitive manner. This is the second theme of the paper, which is introduced next.

\section{Teaching in a More Culturally Sensitive Way}

\section{Minimizing the language barrier}

Nearly all of my students studied English as a second language. I didn't fully appreciate how taxing it can be to study in one's second language until I enrolled in a "Learn to Speak Arabic" class. Learning the student's language was both mentally draining and an eye opening experience for me as I had to question if my practice of having students write a paper or complete a quiz was truly assessing their knowledge of the material, or was I testing more of their ability to communicate in English? Even though the institution's language of instruction is English, I believe to be fair I need to strive for assessment methods that examine their understanding of material which does not rely on one modality (e.g., written work).

Other teaching strategies to minimize the language barrier in the classroom, many of which evolved from asking the students for feedback, include: (a) speaking slowly and clearly. As Crismore (2003) shares in her journal about teaching Malaysian students, "I had to learn to speak more slowly so that the students could process what I said without getting serious cognitive overload" (p. 381); (b) providing handouts that amplify the course lecture and have been modified for ease of reading; (c) allowing ample time for students to copy information 
from the whiteboard; (d) starting each class with a brief review from the previous lesson; and (e) in support of Crismore's recommendation, anticipate the English words and phrases students may not understand and be prepared to define and explain these terms in advance.

\section{Learning from the students}

One of the most valuable strategies I used to gain insight into what the students needed from me so I could be an effective professor in an unfamiliar culture was for them to provide me with anonymous written feedback. Every few weeks, sometimes weekly, I asked students to complete a feedback form on my performance. Sometimes, I designed the questions to elicit specific feedback, however in most cases, I use a generic form (see Appendix B). Although this type of information could be elicited verbally, I found there would be hesitation and a sense of wanting to protect me if I did not provide a written opportunity.

The information I gleamed from these informal forms was extremely useful. For example, I learned that when a student is at a loss for words they deeply appreciate being able to articulate their thoughts in Arabic and then with the assistance of the other students translate it into English. This allows the student to retain her original point without it being lost to frustration. I also received feedback that stories and real life examples provide a meaningful context to the material under discussion, particularly since most of their textbooks are western based. This strategy tapped into their culture's way of knowing and transferring information to each other; namely, poetry and story telling.

\section{Workload and homework}

As previously mentioned, students often find it difficult to complete homework. However, rather than reducing my expectations, I encouraged them to adopt more effective time management skills while on campus to accomplish their work. These students are no different from other postsecondary students I taught in Canada in terms of having poor time management skills. Consequently, students will complain about the workload, particular during the middle of the term. Aside from validating their concerns that "yes, it is a very busy time of the year" and acknowledging the sacrifices they are having to make to get an education, I borrowed an effective phrase from one of my colleagues (Dan Crocco) when responding to a student's complaint about workload as he introduces the incentive to work as hard as his past students have: "Would you want me to believe you are less capable than my Canadian students?" I have used this phrase numerous times and it seems to help some of the students gain a new perspective on their workload. 
In summary, this second theme of being more culturally sensitive in the higher education classroom requires the professor to become much more aware of their teaching style. It is necessary to be flexible while maintaining a high standard for student achievement. The third theme in this article builds upon the previous theme by introducing strategies to make a Western curriculum more culturally relevant to the students.

\section{Using Culturally Relevant Material to Teach Western Concepts}

One of the most fascinating aspects of my teaching duties in the UAE was adapting Western material to the Emirati culture. As explained by Walker and Dimmock (2000), although many Western concepts are taught in non-Western societies, it is culturally relevant and promotes critical learning when students examine perspectives other than Western's principles. It is also valuable for students to investigate how cultures influence the construction of knowledge (Huerta, 1999). For example, one of the topics discussed at length in a course textbook is teen-age dating. In this culture, women do not date as their future husbands are usually introduced to them by their family. Presenting the textbook material would not be very useful to the students but discussing the transition experience would be relevant, if it was from their perspective. However, it was very difficult to find academic information that was from the Emirati perspective (e.g., what feelings did Emirati teens feel when they were introduced to their future husband? How did these feelings impact their school work? Relationships with peers?). To link the course material to Emirati issues, I had to rely heavily on the news media and a three-step process I developed, which will be outlined below.

\section{Use of the local newspaper}

Local newspapers proved to be a gold mine for evidence of how their society approaches topics under discussion. Such articles served as starting points for discussions and/or were used as examples to demonstrate various concepts the students needed to learn. For example, in class discussions on infertility, students would share their beliefs as to the causes for couples not being able to conceive. Responses would range from myths to the fear that the husband would blame the wife and marry another woman. It was a topic that seemed to hold great shame. In the local newspaper, I found articles that referenced fertility treatment centers in the UAE as well as stories of how couples coped with not being able to conceive. For many students, they were not aware of these services and told me that they would feel too embarrassed to approach this topic with their doctor. However, by presenting information from their own country, it allowed them to challenge some of their beliefs. I believe this strategy was much more effective than presenting the material solely as a lecture. 


\section{The three-step process}

To tackle the problem of not having information on the Emirati people or their culture, I developed a three step procedure that works well when trying to adapt western material to a different culture. During the first step, I elicited as much discussion as possible on the topic under investigation. My aim was to understand what the students believed, why they believed it, explore the implications of what they believed as well as inquire how these issues have changed over time, and so on. The second step entailed presenting the required course material but instead of relying on Western generated examples, I use the material gained from step one. The third and last step is relates new concepts to familiar ones, focusing on two areas: (a) comparing and contrasting western principles/concepts taught in step two with their worldviews gain from step one; and (b) reviewing how the information presented to them in the second step could be applied in their culture and in their country. For example, to facilitate this third step, listed below are some of the questions I use:

- Share with me how your parents or grandparents would react to this Western theory of

- Who in your family would agree/disagree with this theory? Do you agree? Why?

- If you could speak to the author of this theory, what would you tell him is missing from his theory, as applied to the Emirati people?

- How could you adapt this theory to your culture so it made sense to your grandparents?

- And, from everything presented to you (in stage two), what would be three things you hope your society would implement?

In my experience, at the beginning of the term the students often appear hesitant to offer their opinion. I found it helpful to acknowledge to the students that it takes time to trust me to share their views and I would also remind them to only share what they feel comfortable sharing. I would also invite students to share their opinions with each other (e.g., in pairs, in small groups). Another strategy that worked well was to have students write their comments on pieces of paper without revealing their identity. I would collect the pieces of paper and read the comments aloud and then ask for comments, reactions and additional examples. Essentially, when eliciting personal opinions from the students, it is best to work a a pace that acknowledges the students need for safety and to assure them that their comments will 
be respected. Once the students feel comfortable sharing their ideas, the discussions about their culture tend to be active and informative.

\section{Accommodating various Muslim and Emirati practices}

The last theme to be reviewed in this article addresses a very specific topic, how to accommodate students' religious practices and customs in the post secondary classroom. It is important that a professor unfamiliar with the student's religion engage in research to understand the meaning and importance of the student's religious customs. The following section will address three topics despite a multitude of areas that could be addressed. The reader is advised to examine the work of Haq (1997) and Ahmad and Bagby (2002) for additional insight into the Muslim faith as it relates to the school environment.

\section{Ramadan}

Teaching during the Ramadan holy month was a new experience for me as for approximately one month Muslims are not allowed to drink or eat from basically sunrise to sunset (times vary). Where I worked, the academic institution accommodated the students by holding classes for half the allotted time (e.g., a 60 min class becomes a 30 min class). However, as a professor, I am still required to cover the same amount of material despite losing a significant portion of class time. This presents some unusual problems as it is difficult to assign homework during this month of fasting as students are often extensively involved in social events after school, some of which extend well into the night. This is a time when family and relatives gather at each other's homes and enjoy late evening feasts. Students have shared with me that they may not go to bed until three or four in the morning and then have to get up early to attend university.

My strategy during the month of Ramadan was to have students work and present on group assignments. Given that completing homework outside of class time was difficult to accomplish, I would give class time for the students to work on their projects. In addition, the presentations would only be for $15-20$ mins as speaking for long periods without drinking fluids can be taxing.

It is interesting to observe that students engage in their fasting with positive attitudes. As Ahmad and Bagby (2002) explain, these holy days move beyond self-discipline into a deep spiritual quest as the fasting ritual is designed to strengthen their commitment to their faith as well as further refine their character. Even with these powerful incentives to engage in the rituals of Ramadan, I believe it is still highly respectful to be cognizant of the fact that although the students may not complain, they may feel tired, weak and irritable without having any food or water during the day. 


\section{Clothing}

All the students I teach wear abayas (a long black robe) and hijabs (a head cover for hair and ears). Many of the students in my classes also prefer to cover their faces (e.g., will wear a niqab or a black veil) when a male is present in the room. Thus, men are instructed to knock and wait before entering a classroom with female students. I discovered it is respectful to announce in advance to the students if a male may be visiting the classroom (e.g., as a guest speaker, IT staff, etc.) as not all students bring their niqabs to class as they prefer to leave them in their lockers. If a male is present, this then puts them in an awkward and potentially embarrassing position as they do not have their niqab.

Another comment about clothing pertains to instructor's clothing. When I informally asked my students what advice they would want me to share with faculty new to the UAE, a number of them mentioned that when female faculty dress conservatively, they interpret it as a sign of respect. To them, conservative means wearing loose clothing, tops that cover the arms at least to the elbow, and skirt lengths at or below the knees.

\section{Animals}

For Muslims, pork is a forbidden food (haraam). Thus, it is respectful to avoid using references to pigs. I also learned that it is not common for Emirati families in the UAE to have house pets. So I try to be respectful by limiting my use of references to animals.

\section{Summary \& Conclusion}

This article advocates for professors to make a concerted effort to be more culturally sensitive when there are cultural and linguistic differences between post secondary students and the professor. When teaching overseas, teachers need to make a genuine effort to understand their new local community (Ward, 1999). This entails becoming familiar with the community's culture, religious customs, and beliefs. Sometimes this information can be learned from published material, however, in many cases there is a lack of this material, particularly in new developing countries such as the UAE. To address this gap of knowledge, this article provides ample suggestions based on my experience to create a safe and trusting classroom environment so students are more willing to share how they construct and evaluate knowledge based on their worldviews. This information can then be used to make the course content more relevant to the student's experiences (Herman \& Bailey, 1991). It also allows the student to feel safe to engage in critical reflection as students realize diversity is welcomed by the professor. 
Certainly, the challenge of becoming more culturally aware in the university classroom is a journey that will take time. In fact, Marulis (2000) believes this process needs to be allencompassing: It needs to become part of the person's mental fabric as it is a way to live and be in a world that has so many cultures.

\section{References}

Ahmad, N., \& Bagby, I. (2002). Schools adapting to Muslim holy month. Education Week, 22(13), 42-48. Retrieved February 28, 2003 from EBSCO database.

Anderson, H., \& Goolishian H. (1992). The client is the expert: A non-knowing approach to therapy. In S. McNamee \& K. J. Gergen (Eds.), Therapy as social construction (pp. 25-39). Newbury Park, CA: Sage.

Crismore, A. (2003). An American woman teaching in Malaysia: Remembering the obstacles and successes. Journal of Adolescent \& Adult Literacy, 46(5), 380-385.

Retrieved February 18, 2003 from ProQuest database.

Haq, F. (1997, September 19). Who will teach the teachers about Muslims? Inter Press Service. Retrieved February 18, 2003 from ProQuest database.

Herman, W., \& Bailey, M. (1991). Recommendations for teaching overseas. College Teaching, 39(3), 177-121. Retrieved February 22, 2003 from ProQuest database.

Huerta, G. (1999). Barriers to the implementation of multicultural education in a secondary teacher preparation program. The High School Journal, 82(3), 150-165. Retrieved February 18, 2003 from ProQuest database.

Marulis, L. (2000). Anti-bias teaching to address cultural diversity. Multicultural Education, 7(3), 27-32. Retrieved February 22, 2003 from ProQuest database.

McGoldrick, M., Gerson, R., \& Shellenberger, S. (1999). Genograms: Assessment and intervention ( $2^{\text {nd }}$ Ed.) NY: Norton.

Ndura, E. (2003). A multicultural education instructor's reflective self-analysis: Facing the challenge of teaching and learning. Multicultural Education, 11(2). Retrieved February 18, 2003 from ProQuest database.

Rogers, C. (1980). A way of being. Boston: Houghton-Mifflin.

Walker, A., \& Dimmock, C. (2000). One size fits all? Teacher appraisal in a Chinese culture. Journal of Personnel Evaluation in Education, 14(2), 155-178.

Ward, M. (1999). Managing student culture and culture shock: A case from European Tirol. Anthropology and Education Quarterly, 30(2), 228-238. Retrieved February 18, 2003 from ProQuest database.

\section{About the Author}

Dawn Lorraine McBride, Ph.D., is Canadian and is a professor and psychologist, who currently teaches psychology in the United Arab Emirates at Zayed University. She has been teaching at a post secondary level for over six years and one of her research areas is exploring cross cultural issues in counselling and counsellor education. 


\section{Appendix}

\section{INTRODUCING MYSELF TO PROFESSOR DAWN}

(Please answer as many questions as you want. Thank you)

Your name:

Your

ID:

Your major:

I do not know my major yet

Are you married?

$\square$ yes IF YES: For how long? How many children do you have?

$\square$ no

$\square$ engaged IF YES: When is the wedding?

When is your birthday?

How old are you?

What has been your favorite course at Zayed

University?

How long have you been a student at ZU?

Why did you decide to go to University? Was it your decision?

What type of career / job would you like to have? (e.g., teacher, social worker, staying at home and raising my children, working in a hospital, etc.). WHY do you want this career? 
Please, if you like, tell me something about yourself to help me get to know you. E.g., your hobbies, something about your family, your favorite TV show, etc.

Appendix B

Student Feedback Opportunity - version 1

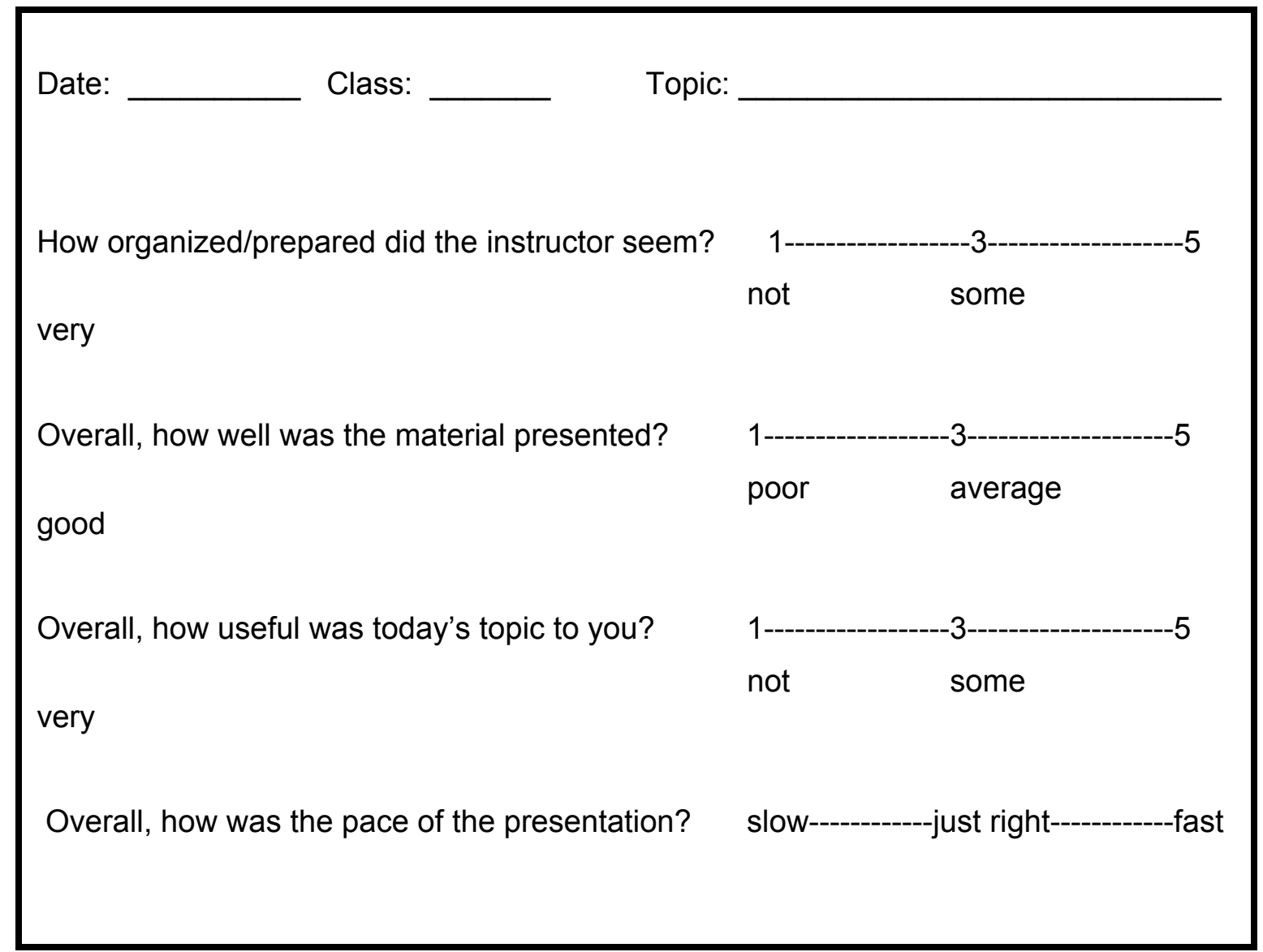


What I liked best about today's class was:

What I liked least about today's class was:

One last thing I would like to say is: 